\title{
Malonic Acid Half Thioesters (MAHTs) as Efficient Enolate Precursors in Biomimetic Catalysis
}

\section{Han Yong Bae}

Department of Chemistry, Sungkyunkwan University, Suwon 440-746, Republic of Korea hanyongbae@gmail.com

Published online: 18.02 .2015

DOI: 10.1055/s-0034-1380269; Art ID: st-2014-v0508-v

\section{Introduction}

In the biosynthesis of polyketides and fatty acids, nature manipulates the enzymatic activation of malonic acid half thioesters (MAHTs) to generate thioester enolates, which undergo a chain elongation step by a decarboxylative Claisen condensation. Inspired by the biocatalytic process, scientists have attempted to mimic nature's approach of decarboxylative organic reactions using bench-stable MAHTs as the efficient C2-unit nucleophiles and discovered diverse catalytic asymmetric processes using transitionmetal catalysts as well as organocatalysts. ${ }^{1}$
Han Yong Bae received his B.Sc. (2010) and M.Sc. (2012) degrees from Sungkyunkwan University. He is currently a Ph.D. student under the supervision of Professor Choong Eui Song, focusing on asymmetric organocatalysis. In 2012, he received the Global Ph.D. Fellowship from the Ministry of Education in Korea.

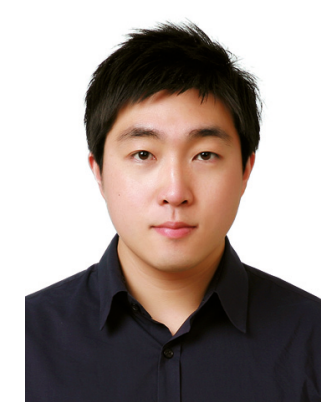

Owing to the highly versatile nature of the thioester moiety, the resulting products can be smoothly converted into a variety of useful functional groups such as alcohol, amide, aldehyde, ketone, ester, carboxylic acid derivatives, and cross-coupled products. ${ }^{2}$

The general synthetic strategy for MAHTs is shown in Scheme $1 .^{3}$

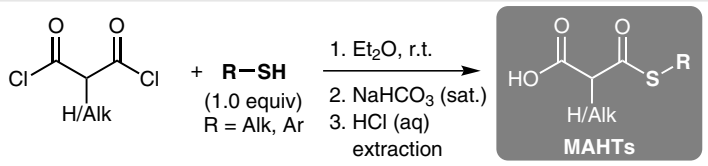

Scheme 1 General procedure for the preparation of MAHTs

Table 1 Use of Malonic Acid Half Thioesters (MAHTs) as Efficient Enolate Precursors in Biomimetic Catalysis

(A) Claisen Condensation with Phenyl Thioacetate: In 1978, a seminal study for the utilization of MAHTs in organic synthesis was reported. Mimicking type I polyketide synthase (PKS) from nature, the decarboxylative Claisen condensation of $n$-butyl substituted MAHT to phenyl thioacetate was disclosed by Kobuke and Yoshida, ${ }^{3 a}$ using imidazole with magnesium acetate as efficient reaction promoters.

(B) Metal-Catalyzed Aldol Reaction with Aldehydes: An achiral version of $\mathrm{Cu}$ (II)-catalyzed decarboxylative aldol reactions of aldehydes with MAHTs was reported by the Shair group in 2003, which is the first example of mimicking type II PKS. ${ }^{4 a}$ Subsequently, Cozzi ${ }^{4 b}$ and Shair ${ }^{4 c}$ independently reported asymmetric decarboxylative aldol reaction of aldehydes with MAHTs catalyzed by $\mathrm{Cu}(\mathrm{OTf})_{2}$ with chiral ligands. In particular, Shair reported the use of $\mathrm{Cu}(\mathrm{II}) / \mathrm{bis}$ (oxazoline) $[(R, R)-\mathbf{1}]$ to afford alkyl substituted $\alpha$-methyl- $\beta$-hydroxy thioesters in good to quantitative yields with excellent enantioselectivities.
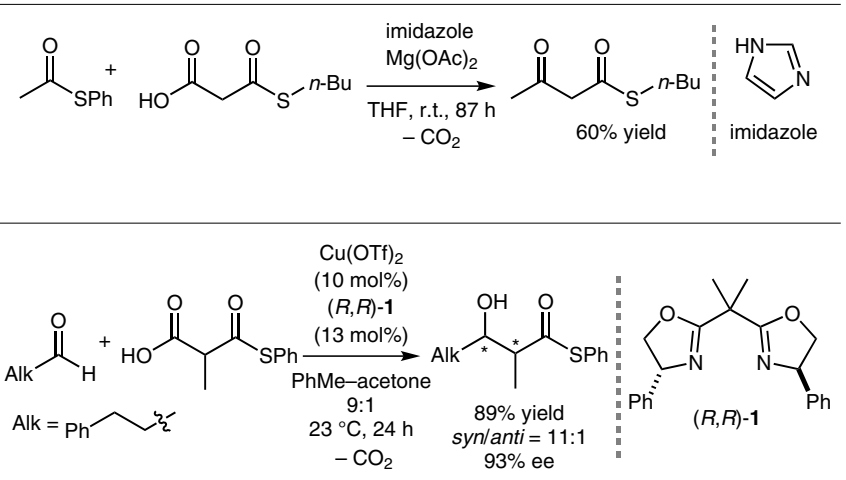

(C) Organocatalytic Aldol Reaction with Aldehydes: Song, List and co-workers reported the first example of enantioselective organocatalytic decarboxylative aldol reaction of MAHTs with $\alpha$-unsubstituted aldehydes using Cinchona-derived sulfonamide organocatalyst $2 .{ }^{5}$ The aldol products were readily transformed into enantioenriched aldehydes as well as amides, which are the key intermediates for the synthesis of bioactive compounds such as fluoxetine, tomoxetine, paroxetine, and duloxetine.

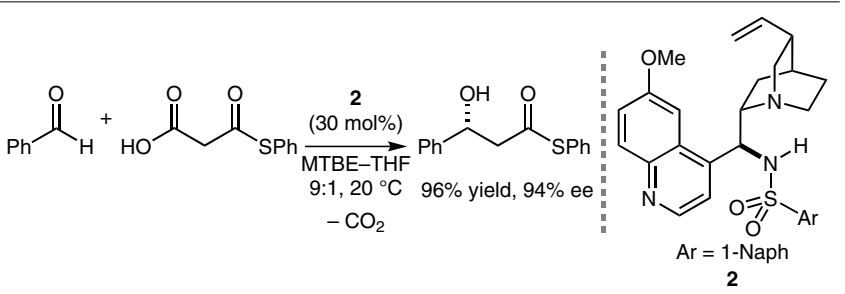


(D) Organocatalytic Mannich Reaction with Imines: In 2007, Ricci et al. reported the first organocatalytic decarboxylative Mannich reaction of MAHTs with N-protected imines catalyzed by Cinchonaderived $\beta$-isocupreidine (3). ${ }^{6 a}$ Optically active $\beta^{3}$-amino thioesters were obtained in good yields with up to $79 \%$ ee. Later, a similar protocol was reported by the Tan group, in which chiral guanidine was utilized as an efficient organocatalyst. ${ }^{\mathrm{b}}$

\begin{abstract}
(E) Organocatalytic Mannich Reaction with Ketimines: Shibata and co-workers reported enantioselective decarboxylative addition of MAHTs to ketimines catalyzed by Cinchona-based $N$-heteroarenesulfonamide. ${ }^{7}$ The Mannich-type reaction afforded chiral $\beta$-aminothioesters incorporating a quaternary carbon center in excellent yields with $78-83 \%$ ee. 8-Quinoline sulfonylated sulfonamide 4 proved to be the most effective catalyst in terms of chemical yield and enantioselectivity $(90 \%, 83 \%$ ee). The resulting product was readily converted into AG-041R, gastrin/cholecyctokinin-B receptor antagonist in three steps.
\end{abstract}

(F) Organocatalytic Michael Addition Reaction with Nitroolefins: The first asymmetric decarboxylative Michael addition reactions of MAHTs to diverse nitroolefins were disclosed by the Wennemers group, ${ }^{8 \mathrm{a}}$ using $20 \mathrm{~mol} \%$ of Cinchona-derived urea catalyst $\mathbf{5}$ as an efficient promoter. Good yields with moderate enantioselectivities (55-67\% ee) were achieved in THF. High enantioselectivities (73$90 \%$ ee) were obtained in ethyl vinyl ether (EVE) although yields were slightly decreased. They expanded this protocol to the synthesis of antidepressant $(R)$-rolipram. More recently, the groups of Shibasaki ${ }^{8 b}$ and Song ${ }^{8 c}$ independently reported the optimization studies of the same reaction using heterobimetallic Ni/La-Salan complex and Cinchona-derived squaramide organocatalyst, respectively.

\section{Acknowledgment}

We are grateful for the financial support provided by the Ministry of Science, ICT and Future Planning (NRF-2014R1A2A1A01005794 and NRF-2012H1A2A1001158), and the Ministry of Trade, Industry and

\section{References}

(1) For reviews, see: (a) Pan, Y. H.; Tan, C. H. Synthesis 2011, 2044. (b) Bernardi, L.; Fochi, M.; Franchini, M. C.; Ricci, A. Org. Biomol. Chem. 2012, 10, 2911. (c) Wang, Z. L. Adv. Synth. Catal. 2013, 355, 2745. (d) Nakamura, S. Org. Biomol. Chem. 2014, 12, 394.

(2) For transformations of thioesters to various functional groups, see: Burhardt, M. N.; Ahlburg, A.; Skrydstrup, T. J. Org. Chem. 2014, 79, 11830 and references therein.

(3) (a) Kobuke, Y.; Yoshida, J.-i. Tetrahedron Lett. 1978, 19, 367. (b) For a recent report for large scale synthesis of MAHTs and references therein, see: Bew, S. P.; Stephenson, G. R.; Rouden, J.; Martinez-Lozano, L. A.; Seylani, H. Org. Lett. 2013, 15, 3805.

(4) (a) Lalic, G.; Aloise, A. D.; Shair, M. D. J. Am. Chem. Soc. 2003, 125, 2852. (b) Orlandi, S.; Benaglia, M.; Cozzi, F. Tetrahedron Lett. 2004, 45, 1747. (c) Magdziak, D.; Lalic, G.; Lee, H. M.; Fortner, K. C.; Aloise, A. D.; Shair, M. D. J. Am. Chem. Soc. 2005, 127,7284 .


Energy (Fundamental R\&D Program for the Core Technology of Materials).

(5) Bae, H. Y.; Sim, J. H.; Lee, J.-W.; List, B.; Song, C. E. Angew. Chem. Int. Ed. 2013, 52, 12143.

(6) (a) Ricci, A.; Pettersen, D.; Bernardi, L.; Fini, F.; Fochi, M.; Herrera, R. P.; Sgarzani, V. Adv. Synth. Catal. 2007, 349, 1037. (b) Pan, Y.; Kee, C. W.; Jiang, Z.; Ma, T.; Zhao, Y.; Yang, Y.; Xue, H.; Tan, C.-H. Chem. Eur. J. 2011, 17, 8363.

(7) Hara, N.; Nakamura, S.; Sano, M.; Tamura, R.; Funahashi, Y.; Shibata, N. Chem. Eur. J. 2012, 18, 9276.

(8) (a) Lubkoll, J.; Wennemers, H. Angew. Chem. Int. Ed. 2007, 46, 6841. (b) Furutachi, M.; Mouri, S.; Matsunaga, S.; Shibasaki, M. Chem. Asian J. 2010, 5, 2351. (c) Bae, H. Y.; Some, S.; Lee, J. H.; Kim, J.-Y.; Song, M. J.; Lee, S.; Zhang, Y. J.; Song, C. E. Adv. Synth. Catal. 2011, 353, 3196. 